\title{
Pain problems for patients with mild and moderate chronic obstructive pulmonary disease - a community-based study in Shanghai
}

This article was published in the following Dove Press journal:

Journal of Pain Research

15 September 2017

Number of times this article has been viewed

\author{
Tian Xiao',* \\ Xianfeng Zhou ${ }^{2, *}$ \\ Yun $\mathrm{He}^{1}$ \\ Yue Chen ${ }^{3}$ \\ Hua Qiu ${ }^{2}$ \\ Sheng Zhang' \\ Xianglin Wei' \\ Kang $W_{u^{2}}$ \\ Xiaonan Ruan ${ }^{2}$ \\ Na Wang' \\ Chaowei $\mathrm{Fu}^{\prime}$
}

'Department of Epidemiology, School of Public Health, Key Laboratory of Public Health Safety, Pudong Institute of Preventive Medicine, Fudan University, ${ }^{2}$ Department of Chronic Disease, Pudong New Area Center for Disease Control and Prevention, Shanghai, China; ${ }^{3}$ School of Epidemiology and Public Health, Faculty of Medicine, University of Ottawa, Ottawa, ON, Canada

*These authors contributed equally to this work.

Correspondence: Chaowei Fu Department of Epidemiology, School of Public Health, Key Laboratory of Public Health Safety, Pudong Institute of Preventive Medicine, Fudan University, 8-3।3, I30 Dong'an Road, Shanghai 200032, China

Tel/Fax +86 2I5 423 78II

Email fcw@fudan.edu.cn
Background: Chronic obstructive pulmonary disease (COPD) is a great public health burden worldwide. Few studies have focused on pain problems in patients with mild and moderate COPD in Chinese community settings.

Methods: A cross-sectional study of 283 patients with mild and moderate COPD was conducted in six communities that were randomly sampled in Pudong New Area of Shanghai, China, in 2016. A face-to-face interview was conducted to collect data on personal characteristics and health conditions. The short form McGill Pain Questionnaire and the COPD assessment test (CAT) were applied to evaluate pain problems and health status, respectively.

Results: Among 283 subjects, more than one third (37\%) had pain problems indicated by the present pain intensity (PPI) scale. COPD patients aged $<65$ years with exacerbation in the past 12 months or a CAT score of $\geq 10$ had a significantly higher score in affective dimension. Female sex, COPD severity, and length of disease were significantly related to higher scores of the sensory dimension. Those with moderate COPD or a CAT score of $\geq 10$ had significantly higher scores of visual analog scale than those with mild COPD or a CAT score $<10$. Patients with moderate COPD had a higher rank of PPI than those with mild COPD.

Conclusion: Pain was common in patients with mild and moderate COPD in the community settings of Shanghai, China. Severity of COPD and CAT score were significantly related to the prevalence of pain. Intervention measures should be developed to improve pain problems for COPD patients.

Keywords: pain, COPD, Chinese, community settings, prevalence

\section{Background}

Chronic obstructive pulmonary disease (COPD) is a chronic pulmonary disease characterized by persistent airway limitation, which is not fully reversible but progressive. ${ }^{1}$ In 2011, COPD was the fourth leading cause of mortality around the world, and was expected to rise up to the third in 2020 globally. ${ }^{2}$ In China, among adults $>40$ years of age, the prevalence of COPD has reached $8.2 \%$ based on a national survey. ${ }^{3}$ COPD costed 50 billion dollars in USA in 2010 and 36.9 billion dollars in China in 2011. ${ }^{4,5}$ Therefore, COPD has become one of the most expensive diseases to treat. ${ }^{2-6}$

As a chronic and inflammatory disease, COPD patients have a wide range of responding symptoms, such as cough, breathlessness, anxiety, depression, and fatigue. ${ }^{7-14}$ Recent studies have paid increasing attention to pain problems and found that approximately half of COPD patients suffered from pain and the risk of pain increased with the severity of COPD. ${ }^{15-20}$ Pain is a very important issue for COPD patients, and also complex depending on its nature, intensity, localization, source, and frequency. 
A previous study showed that the intensity of pain was significantly associated with factors such as 6-minute walk test, forced expiratory volume in one second (FEV1), body mass index, and commodities in a population with COPD. ${ }^{21-23}$ However, few studies have focused on the characteristics and influencing factors of pain in Chinese COPD patients at early stages. This study aimed to explore pain problems and associated factors for patients with mild or moderate COPD in China.

\section{Materials and methods}

\section{Study site and subjects}

A cross-sectional study was carried out in Pudong New District of Shanghai, China, in 2016. Six communities were randomly selected from 46 communities in the district to recruit patients with mild (FEV1 $\geq 80 \%$ predicted and FEV1/ forced vital capacity $[\mathrm{FVC}]<0.7)$ or moderate $(50 \% \leq \mathrm{FEV} 1$ predicted $<80 \%$ and FEV1/FVC $<0.7)$ COPD. ${ }^{24}$ A patient was included in the study if he or she 1) met the diagnosis criterion of COPD defined by 2016 Global initiative for chronic Obstructive Lung Disease (GOLD) recommendations; ${ }^{24}$ ) had either mild or moderate COPD; 3) was able to offer informed consent and medical chart; 4) was a local resident aged 40-70 years; and 5) was able to complete the questionnaire interview and lung function test. Patients with serious or unstable conditions, such as cardiovascular, neurological, and musculoskeletal diseases, who needed to be treated as inpatients, were excluded from the research. Subjects with cognitive impairment and mobility limitation were also excluded. A total of 283 out of 300 recruited COPD patients were eligible and included in the study with a response rate of $100 \%$.

\section{Applied scales on questionnaire}

The short form McGill Pain Questionnaire (SF-MPQ) was used to measure the intensity of pain for COPD patients. ${ }^{19,21}$ Scores of different parts of SF-MPQ were calculated to characterize the pain problems. The SF-MPQ consists of three sections. 1) A list of 15 words including 11 sensory descriptive and four affective descriptive terms as pain rank index (PRI) is used to describe pain, which is scored out of 45 by the respondent on a four-point scale (0-3) of each term. 2) A visual analog scale (VAS) on a $100 \mathrm{~mm}$ line is scored from 0 to 100 to rate the severity of the most recent pain. 3) The current intensity of pain is assessed by present pain intensity (PPI) scale with five ranks from "no pain" to "extreme pain". ${ }^{25}$ This form has been widely applied to assess the severity of patients' pain and proved to be reliable and valid. ${ }^{26}$ The COPD assessment test (CAT) scale is selfadministered for disease-specific health status with eight questions and each with five ranks from 1 to 5 indicating symptoms from "never " to "always" and total scores ranging from 8 to 40 representing the best health status to the worst health status. ${ }^{27}$ A CAT score of $>10$ indicates worse health status of patients than those with CAT score of $\leq 10 .{ }^{28}$

\section{Measurements and variable forms}

Spirometry was performed to obtain FEV1 and FVC values as well as FEV1 \% predicted to determine COPD severity with criteria provided by the 2016 GOLD recommendation. ${ }^{24}$ FEV1 was tested 10 minutes after short-acting beta -agonist $^{-}$ had been given, and FEV1 along with FVC was the largest value obtained from one of the technically satisfactory curves which was similar to determining the FEV1/FVC ratio. Demographic and clinical characteristics were determined by asking questions such as "what is your birth date?" or "in which year and month were you diagnosed with COPD?" or "which level of education do you have? 1) <9 years; 2) 9-10 years; 3) 11-12 years; 4) $\geq 12$ years". The information was cross-checked with their medical charts. Education level was regrouped into two categories: completed primary middle school (9 years, free and compulsory education warranted by the Chinese government) or not. Regular medication use for COPD meant that self-reported drug use must match the recent prescription in the medical chart.

\section{Quality control}

Each time two investigators were involved with the interview. One investigator initiated the interview and completed the questionnaires while the other investigator double-checked the information.

\section{Informed consent}

Written informed consent was obtained from all participants. They were permitted to withdraw from the study at any time without negative consequences. Ethical approval for this study was issued by the Institutional Review Board of the Fudan University School of Public Health.

\section{Statistical analysis}

Data were entered twice with Epidata 3.1 and statistical analysis was performed in SAS 9.2 (SAS Institute Inc., Cary, NC, USA). Chi-square or Fisher's test was used for categorical variables, and Student's $t$-test, one-way analysis of variance, or Wilcoxon test for continuous variables. Risk factors for pain (PPI $>0$ vs PPI $=0$ ) were identified, and their 
crude odds ratios (cORs), adjusted odds ratios, and 95\% confidence intervals were estimated using logistic regression models. All statistical tests were two-sided at the significance level of 0.05 .

\section{Results}

\section{Demographic and clinical characteristics}

Of 283 subjects, $52 \%$ were female and the average age for all the participants was $61.5 \pm 6.0$ years. As shown in Table 1 , about two fifths were either former or current smokers and one third worked in a hazardous air environment for at least 1 year. The average COPD course was $11.3 \pm 14.0$ years with a median total CAT score of $15 \pm 7(\mathrm{M} \pm \mathrm{IQR})$. Of the patients, $27.9 \%$ experienced at least one exacerbation in the past 12 months, and $53.0 \%$ had at least one comorbid condition (Table 1).

\section{Pain characteristics measured by SF-MPQ} Overall, 104 (37\%) patients reported pain problems (PPI $>0$ ). Table 2 presents the average scores of sensory dimension (PRI; 1.2 \pm 2.6 ), emotion dimension (PRI; 1.1 \pm 1.7 ), VAS $(0.9 \pm 1.5)$, and PPI $(0.5 \pm 0.8)$. Patients aged $<65$ years had a significantly higher score in affective dimension compared with older patients $(P=0.042)$. Women had a significantly higher score in the sensory dimension than men $(P=0.033)$. Those with at least one exacerbation in the past 12 months had a significantly higher score of pain in affective dimension than those without exacerbation $(P=0.014)$. Patients with COPD for $\geq 10$ years scored higher than those with the disease for $<10$ years in sensory dimension $(P=0.033)$. Compared to patients with a CAT score of $<10$, those with a CAT score of $\geq 10$ had substantially worse pain indicated by affective dimension $(P=0.041)$ or VAS $(P=0.032)$. Patients with moderate COPD had more severe pain indicated by sensory dimension $(P=0.028)$, VAS $(P=0.003)$, or PPI $(P=0.002)$ than those with mild COPD (Table 2).

\section{Associated factors for pain in COPD patients}

Logistic regression model showed that patients with moderate COPD were significantly more likely to have pain problems than those with mild COPD. The cOR was 12.8 for PPI ( $>0$ vs $0, P=0.018$ ) and 3.8 for the CAT score ( $\geq 10$ vs $<10$, $P=0.037)$. After adjustment for age, gender, smoking, average household income, COPD course, regular treatment for COPD exacerbation, and comorbidities, the corresponding odds ratios were $21.8(P=0.006)$ and $4.7(P=0.029)$ (Table 3$)$.

\section{Discussion}

Pain problems were prevalent in COPD patients but only few studies were carried out among COPD cases at mild stage. ${ }^{15-18}$ In this community-based study of mild or moderate COPD patients, more than one third had some pain problems indicated by PPI of SF-MPQ, which was comparable to the results of previous studies with the range of $32 \%-72 \%$ in other countries. ${ }^{15-18}$ The prevalence of pain varied with

Table I Demographic and clinical characteristics of COPD patients

\begin{tabular}{|c|c|c|c|c|}
\hline \multirow[t]{2}{*}{ Characteristics } & \multicolumn{2}{|l|}{ Gender } & \multirow[t]{2}{*}{ Total } & \multirow[t]{2}{*}{$P$-value } \\
\hline & Male & Female & & \\
\hline Number [n (\%)] & $136(48.1)$ & I47 (5।.9) & $283(100)$ & \\
\hline Age (year) $(\mathrm{X} \pm \mathrm{SD})$ & $62.2 \pm 5.4$ & $60.9 \pm 6.5$ & $61.5 \pm 6.0$ & 0.194 \\
\hline $\mathrm{BMI}\left(\mathrm{kg} / \mathrm{m}^{2}\right)(\mathrm{X} \pm \mathrm{SD})$ & $24.7 \pm 3.9$ & $25.4 \pm 4.1$ & $25.1 \pm 4.0$ & 0.146 \\
\hline Ex/current drinker (n [\%]) & $49(36.0)$ & $4(2.7)$ & $53(18.7)$ & $<0.001$ \\
\hline Ex/current smoker (n [\%]) & I I3 (83.I) & $2(1.4)$ & I I 5 (40.6) & $<0.001$ \\
\hline Regular exercise (n [\%]) & $48(35.3)$ & $52(35.4)$ & $100(35.3)$ & 0.989 \\
\hline Education (years) & & & & 0.540 \\
\hline$<9$ & II I (8I.6) & $124(84.4)$ & $235(83.0)$ & \\
\hline$\geq 9$ & $25(18.4)$ & $23(15.6)$ & $48(17.0)$ & \\
\hline Monthly household income per capita (RMB Yuan), N (\%) & & & & 0.011 \\
\hline$<3,000$ & $59(43.4)$ & $86(58.5)$ & $145(5 \mid .2)$ & \\
\hline$\geq 3,000$ & $77(56.6)$ & $6 I(4 \mid .5)$ & $138(48.8)$ & \\
\hline COPD course (year) $(\mathrm{X} \pm \mathrm{SD})$ & $9.4 \pm 13.8$ & $12.9 \pm 13.9$ & $11.3 \pm 14.0$ & 0.016 \\
\hline CAT score $(M \pm I Q R)$ & $15 \pm 7$ & $16 \pm 7$ & $15 \pm 7$ & 0.689 \\
\hline Regular medication for COPD in the past 12 months (n [\%]) & $49(36.0)$ & $5 \mathrm{I}(34.7)$ & $100(35.3)$ & 0.814 \\
\hline Exacerbation in the past 12 months (n [\%]) & $36(26.5)$ & $43(29.3)$ & $79(27.9)$ & 0.602 \\
\hline Comorbidities (n [\%]) & $63(46.3)$ & $87(59.2)$ & $150(53.0)$ & 0.030 \\
\hline
\end{tabular}

Note: For comparison, $\chi^{2}$ test was used for binary variables, and Student's $t$-test or Wilcoxon nonparametric test was employed for continuous variables; the bold $P$-values indicate statistical significance.

Abbreviations: BMI, body mass index; COPD, chronic obstructive pulmonary disease; CAT, COPD assessment test; SD, standard deviation; IQR, interquartile range. 
Table 2 Pain characteristics from SF-MPQ according to key variables*

\begin{tabular}{|c|c|c|c|c|c|c|c|}
\hline \multirow[t]{2}{*}{ Characteristics } & \multicolumn{3}{|c|}{ PRI score (X士SD) } & \multirow{2}{*}{$\begin{array}{l}\text { VAS } \\
\text { score } \\
(X \pm S D)\end{array}$} & \multicolumn{3}{|c|}{ PPI rank [N (\%)] } \\
\hline & $\begin{array}{l}\text { Sensory } \\
\text { dimension }\end{array}$ & $\begin{array}{l}\text { Affective } \\
\text { dimension }\end{array}$ & Total & & No pain & $\begin{array}{l}\text { Mild } \\
\text { discomfort }\end{array}$ & $\begin{array}{l}\text { Discomfort or } \\
\text { worse }\end{array}$ \\
\hline \multicolumn{8}{|l|}{ Age (years) } \\
\hline$<65$ & $1.3 \pm 3.0$ & $1.2 \pm 1.9$ & $2.5 \pm 4.1$ & $9.6 \pm 16.0$ & $116(62.0)$ & $53(28.4)$ & $18(9.6)$ \\
\hline$\geq 65$ & $1.0 \pm 1.7$ & $0.8 \pm 1.4$ & $1.8 \pm 2.4$ & $6.9 \pm 14.2$ & $63(65.6)$ & $20(20.8)$ & $13(13.6)$ \\
\hline$P$-value & 0.974 & 0.042 & 0.348 & 0.077 & 0.301 & & \\
\hline \multicolumn{8}{|l|}{ Gender } \\
\hline Male & $0.9 \pm 2.0$ & $0.9 \pm 1.6$ & $1.8 \pm 3.1$ & $8.7 \pm 16.3$ & $87(64.0)$ & $32(23.5)$ & $17(12.5)$ \\
\hline Female & $1.4 \pm 3.0$ & $1.2 \pm 1.9$ & $2.6 \pm 4.0$ & $8.8 \pm 14.8$ & $92(62.6)$ & $4 \mid(27.9)$ & $14(9.5)$ \\
\hline$P$-value & 0.033 & 0.279 & 0.013 & 0.537 & 0.573 & & \\
\hline \multicolumn{8}{|l|}{ Severity } \\
\hline Mild & $1.1 \pm 2.6$ & $1.0 \pm 1.7$ & $2.1 \pm 3.6$ & $8.3 \pm 14.9$ & $178(64.7)$ & $70(25.5)$ & $27(9.8)$ \\
\hline Moderate & $3.0 \pm 3.8$ & $1.9 \pm 2.1$ & $4.9 \pm 5.4$ & $25.0 \pm 15.6$ & $\mathrm{I}(12.5)$ & $3(37.5)$ & $4(50.0)$ \\
\hline$P$-value & 0.028 & 0.281 & 0.055 & 0.003 & $0.002 *$ & & \\
\hline \multicolumn{8}{|c|}{ Exacerbation in the past 12 months } \\
\hline No & $1.3 \pm 2.8$ & $0.9 \pm 1.6$ & $2.3 \pm 3.8$ & $8.4 \pm 15.0$ & $129(63.2)$ & $54(26.5)$ & $21(10.3)$ \\
\hline Yes & $0.9 \pm 2.0$ & $1.5 \pm 2.1$ & $2.1 \pm 3.4$ & $9.7 \pm 16.6$ & $50(63.3)$ & $19(24.1)$ & $10(12.7)$ \\
\hline$P$-value & 0.571 & 0.014 & 0.814 & 0.505 & 0.811 & & \\
\hline \multicolumn{8}{|l|}{ Course (years) } \\
\hline$<10$ & $1.0 \pm 2.7$ & $1.1 \pm 1.8$ & $2.1 \pm 3.8$ & $7.8 \pm 13.9$ & $118(65.6)$ & $48(26.6)$ & $14(7.8)$ \\
\hline$\geq 10$ & $1.4 \pm 2.5$ & $1.0 \pm 1.6$ & $2.4 \pm 3.4$ & $10.4 \pm 17.8$ & $61(59.2)$ & $25(24.3)$ & $17(16.5)$ \\
\hline$P$-value & 0.033 & 0.689 & 0.110 & 0.491 & 0.078 & & \\
\hline \multicolumn{8}{|l|}{ CAT score } \\
\hline$<10$ & $0.5 \pm 1.5$ & $0.3 \pm 0.7$ & $0.8 \pm 1.8$ & $3.6 \pm 11.3$ & I8 (85.7) & $3(14.3)$ & $0(0)$ \\
\hline$\geq 10$ & $1.2 \pm 2.7$ & $1.1 \pm 1.8$ & $2.3 \pm 3.7$ & $9.2 \pm 15.7$ & $16 \mid(6 \mid .5)$ & 70 (26.7) & 31 (II.8) \\
\hline$P$-value & 0.051 & $0.04 I$ & 0.009 & 0.032 & 0.065 & & \\
\hline
\end{tabular}

Note: For comparison, $\chi^{2}$ test was used for binary variables (*Fisher's test) and Student's $t$-test or Wilcoxon nonparametric test was employed for comparisons of two independent groups of continuous variables; the bold $P$-values indicate statistical significance.

Abbreviations: PRI, pain rank index; PPI, present pain intensity; VAS, visual analog scale; COPD, chronic obstructive pulmonary disease; CAT, COPD assessment test; SD, standard deviation; SF-MPQ, short form McGill Pain Questionnaire.

Table 3 Factors correlated with the prevalence of pain

\begin{tabular}{|c|c|c|c|c|c|c|c|c|}
\hline \multirow[t]{2}{*}{ Characteristics } & \multicolumn{2}{|c|}{ Pain problem [N (\%)] } & \multirow[t]{2}{*}{ cOR } & \multirow[t]{2}{*}{ c95\% Cl } & \multirow[t]{2}{*}{$P$-value } & \multirow[t]{2}{*}{ aOR } & \multirow[t]{2}{*}{ a95\% Cl } & \multirow[t]{2}{*}{$P$-value } \\
\hline & No pain & With pain & & & & & & \\
\hline \multicolumn{9}{|l|}{ Course (years) } \\
\hline$<10$ & $118(65.9)$ & $62(59.6)$ & 1 & & & 1 & & \\
\hline$\geq 10$ & $61(34.1)$ & $42(40.4)$ & 1.31 & $0.80-2.16$ & 0.288 & 1.43 & $0.83-2.48$ & 0.197 \\
\hline \multicolumn{9}{|l|}{ Severity } \\
\hline Mild & $178(99.4)$ & $97(93.3)$ & 1 & & & I & & \\
\hline Moderate & I $(0.6)$ & $7(6.7)$ & 12.84 & $1.56-105.87$ & 0.018 & 21.83 & $2.43-195.79$ & 0.006 \\
\hline \multicolumn{9}{|c|}{ Exacerbation in the past 12 months } \\
\hline No & $129(72.1)$ & $75(72.1)$ & 1 & & & $\mathrm{I}$ & & \\
\hline Yes & $50(27.9)$ & $29(27.9)$ & 1 & $0.58-1.71$ & 0.993 & 0.9 & $0.5 \mathrm{I}-\mathrm{I} .58$ & 0.719 \\
\hline \multicolumn{9}{|l|}{ CAT score } \\
\hline$<10$ & $18(10.1)$ & $3(2.9)$ & 1 & & & 1 & & \\
\hline$\geq 10$ & 161 (89.9) & 101 (97.1) & 3.76 & $1.08-13.10$ & 0.037 & 4.65 & I.17-18.45 & 0.029 \\
\hline
\end{tabular}

Note: Factors in the adjusted logistic model: gender, age, smoking behavior, monthly household income per capita, disease course, regular medication, COPD severity, exacerbation, comorbidity, and CAT score; the bold $P$-values indicate statistical significance.

Abbreviations: COPD, chronic obstructive pulmonary disease; CAT, COPD assessment test; c95\% Cl, crude $95 \%$ confidence interval; a95\% Cl, adjusted $95 \%$ confidence interval; cOR, crude odds ratio; aOR, adjusted odds ratio.

the severity of COPD. ${ }^{18}$ Our study found that patients with moderate COPD had a significantly increased risk of pain compared with those with mild COPD, reflected by higher scores of PPI, PRI, and VAS, which is not consistent with a previous study that found no significant difference in the prevalence of pain between moderate and extremely severe stages ${ }^{29}$ Instead, some studies revealed that patients with moderate COPD had a higher prevalence of pain than those at other stages of COPD. ${ }^{18,19}$ Such a difference was probably due to varied study populations. Our study suggested that 
pain problems existed at the early stage of COPD, and should be dealt with accordingly. Community health care services may include early interventions for COPD patients with pain, which provide knowledge of pain management for patients, educate health policy makers and health care providers, and improve guidelines of COPD health care and treatment. Since the risk of pain problems increases with severity of COPD, COPD patients should be assessed and queried regularly for pain starting at the early stage of the disease, and pain should be dealt with as needed in time.

Associated factors for pain in COPD patients included female sex, younger age ( $<65$ years), longer course of the disease ( $\geq 10$ years), and exacerbation in the past 12 months, which were consistent with the results from a previous study.$^{30}$ Females were more likely to report pain and other health related problems. ${ }^{30-33}$ After adjustment for important covariates, the associations of COPD severity and CAT score with pain, indicated by PPI, became stronger, which was similar to the results of previous studies. ${ }^{18,29,30,34}$ Pain in COPD, similar to other chronic diseases such as diabetes and cancer, was significantly related to disease severity and adverse disease impacts could include reduced quality of life, anxiety, and depression. ${ }^{35-41}$ More attention must be paid to COPD patients with advanced severity or high CAT scores for their pain problems.

An important highlight of the current study is that the study was community based and had a very high response rate while most previous studies were hospital based and were less representative of COPD patients in community settings. ${ }^{22,30,34,42,43}$ This study included patients with mild COPD, and found that pain was common as well among these patients..$^{20,22}$ There are several limitations to this study. Firstly, the study only included COPD patients at mild and moderate stages, and only involved one city, which reduces the representativeness of the COPD population in general. Secondly, as a cross-sectional study, the evidence was weak for causal linkages between influencing factors and pain. In addition, coexisting chronic pain conditions might bias the estimate of pain prevalence, but they are not common in the Chinese population. ${ }^{44}$ This study only focused on pain occurrence based on one scale of SF-MPQ while many other features of pain, including the nature, location, and frequency of pain, were not investigated.

In conclusion, pain is a common problem for patients with mild and moderate COPD. Severity of COPD and CAT score were significantly related to the prevalence of pain. Intervention measures should be developed to improve pain problems for COPD patients at early stages of the disease.

\section{Acknowledgments}

This work was supported by the National Natural Science Foundation of China (81473038), Delong Foundation of Fudan School of Public Health (DL2015024), Shanghai 3-Year Public Health Action Plan (GWTD2015S04), and Shanghai Leading Academic Discipline Project of Public Health (15GWZK80101). The sponsors have no role in the study design, survey process, data analysis, and manuscript preparation.

\section{Disclosure}

The authors report no conflicts of interest in this work.

\section{References}

1. Vestbo J, Hurd SS, Rodriguez-Roisin R. The 2011 revision of the global strategy for the diagnosis, management and prevention of COPD (GOLD) - why and what? Clin Respir J. 2012;6(4):208-214.

2. Wu M, Zhao Q, Chen Y, Fu C, Xu B. Quality of life and its association with direct medical costs for COPD in urban China. Health Qual Life Outcomes. 2015;13:57.

3. Zhong N, Wang C, Yao W, et al. Prevalence of chronic obstructive pulmonary disease in China: a large, population-based survey. Am J Respir Crit Care Med. 2007;176(8):753-760.

4. Guarascio AJ, Ray SM, Finch CK, Self TH. The clinical and economic burden of chronic obstructive pulmonary disease in the USA. Clinicoecon Outcomes Res. 2013;5:235-245.

5. Chen X, Wang N, Chen Y, Xiao T, Fu C, Xu B. Costs of chronic obstructive pulmonary disease in urban areas of China: a cross-sectional study in four cities. Int J Chron Obstruct Pulmon Dis. 2016;11:2625-2632.

6. Soriano JB, Rodriguez-Roisin R. Chronic obstructive pulmonary disease overview: epidemiology, risk factors, and clinical presentation. Proc Am Thorac Soc. 2011;8(4):363-367.

7. Yamane T, Hattori N, Kitahara Y, et al. Productive cough is an independent risk factor for the development of COPD in former smokers. Respirology. 2010;15(2):313-318.

8. Ohar JA, Sadeghnejad A, Meyers DA, Donohue JF, Bleecker ER. Do symptoms predict COPD in smokers? Chest. 2010;137(6):1345-1353.

9. Mollaoglu M, Fertelli TK, Tuncay FO. Fatigue and disability in elderly patients with chronic obstructive pulmonary disease (COPD). Arch Gerontol Geriatr. 2011;53(2):e93-e98.

10. Miravitlles M. Cough and sputum production as risk factors for poor outcomes in patients with COPD. Respir Med. 2011;105(8):1118-1128.

11. Ulrik CS, Lokke A, Dahl R, et al. Early detection of COPD in general practice. Int J Chron Obstruct Pulmon Dis. 2011;6:123-127.

12. Arikan H, Savci S, Calik-Kutukcu E, et al. The relationship between cough-specific quality of life and abdominal muscle endurance, fatigue, and depression in patients with COPD. Int J Chron Obstruct Pulmon Dis. 2015;10:1829-1835.

13. Martinez CH, Murray S, Barr RG, et al. Respiratory symptoms items from the COPD assessment test identify ever-smokers with preserved lung function at higher risk for poor respiratory outcomes. An analysis of the subpopulations and intermediate outcome measures in COPD study cohort. Ann Am Thorac Soc. 2017;14(5):636-642.

14. Miravitlles M, Ribera A. Understanding the impact of symptoms on the burden of COPD. Respir Res. 2017;18(1):67.

15. Elkington H, White $P$, Addington-Hall J, Higgs R, Edmonds P. The healthcare needs of chronic obstructive pulmonary disease patients in the last year of life. Palliat Med. 2005;19(6):485-491.

16. Solano JP, Gomes B, Higginson IJ. A comparison of symptom prevalence in far advanced cancer, AIDS, heart disease, chronic obstructive pulmonary disease and renal disease. J Pain Symptom Manage. 2006;31(1):58-69. 
17. Lee AL, Harrison SL, Goldstein RS, Brooks D. Pain and its clinical associations in individuals with COPD: a systematic review. Chest. 2015;147(5):1246-1258.

18. van Dam VIE, Groenewegen-Sipkema KH, Spruit-van EM, et al. Pain in patients with COPD: a systematic review and meta-analysis. $B M J$ Open. 2014;4(9):e5898.

19. HajGhanbari B, Holsti L, Road JD, Darlene RW. Pain in people with chronic obstructive pulmonary disease (COPD). Respir Med. 2012;106(7): 998-1005.

20. Bentsen SB, Rustoen T, Miaskowski C. Prevalence and characteristics of pain in patients with chronic obstructive pulmonary disease compared to the Norwegian general population. J Pain. 2011;12(5):539-545.

21. HajGhanbari B, Garland SJ, Road JD, Reid WD. Pain and physical performance in people with COPD. Respir Med. 2013;107(11):1692-1699.

22. Bentsen SB, Rustoen T, Miaskowski C. Differences in subjective and objective respiratory parameters in patients with chronic obstructive pulmonary disease with and without pain. Int J Chron Obstruct Pulmon Dis. 2012;7:137-143.

23. Roberts MH, Mapel DW, Hartry A, Von Worley A, Thomson H. Chronic pain and pain medication use in chronic obstructive pulmonary disease. A cross-sectional study. Ann Am Thorac Soc. 2013;10(4):290-298.

24. Global Initiative for Chronic Obstructive Lung Disease. Global Strategy for the Diagnosis, Management, and Prevention of Chronic Obstructive Pulmonary Disease; 2016. Available from: http://goldcopd.org/globalstrategy-diagnosis-management-prevention-copd-2016/. Accessed December 14, 2016.

25. Melzack R. The McGill Pain Questionnaire: major properties and scoring methods. Pain. 1975;1(3):277-299.

26. Reading AE, Everitt BS, Sledmere CM. The McGill Pain Questionnaire: a replication of its construction. Br J Clin Psychol. 1982;21:339-349.

27. Jones PW, Harding G, Berry P, Wiklund I, Chen WH, Kline LN. Development and first validation of the COPD assessment test. Eur Respir J. 2009;34(3):648-654.

28. Vestbo J, Hurd SS, Agusti AG, et al. Global strategy for the diagnosis, management, and prevention of chronic obstructive pulmonary disease: GOLD executive summary. Am J Respir Crit Care Med. 2013;187(4): 347-365.

29. Christensen VL, Holm AM, Kongerud J, et al. Occurrence, characteristics, and predictors of pain in patients with chronic obstructive pulmonary disease. Pain Manag Nurs. 2016;17(2):107-118.

30. Borge CR, Wahl AK, Moum T. Pain and quality of life with chronic obstructive pulmonary disease. Heart Lung. 2011;40(3):e90-e101.
31. Lamprecht B, Vanfleteren LE, Studnicka M, et al. Sex-related differences in respiratory symptoms: results from the BOLD study. Eur Respir J. 2013;42(3):858-860.

32. Martinez FJ, Curtis JL, Sciurba F, et al. Sex differences in severe pulmonary emphysema. Am J Respir Crit Care Med. 2007;176(3):243-252.

33. Lopez VM, Montes DOM, Halbert RJ, et al. Sex-related differences in COPD in five Latin American cities: the PLATINO study. Eur Respir J. 2010;36(5):1034-1041.

34. Janssen DJ, Wouters EF, Parra YL, Stakenborg K, Franssen FM. Prevalence of thoracic pain in patients with chronic obstructive pulmonary disease and relationship with patient characteristics: a cross-sectional observational study. BMC Pulm Med. 2016;16:47.

35. Bouhassira D, Letanoux M, Hartemann A. Chronic pain with neuropathic characteristics in diabetic patients: a French cross-sectional study. PLoS One. 2013;8(9):e74195.

36. Attal N, Lanteri-Minet M, Laurent B, Fermanian J, Bouhassira D. The specific disease burden of neuropathic pain: results of a French nationwide survey. Pain. 2011;152(12):2836-2843.

37. Smith BH, Torrance N, Bennett MI, Lee AJ. Health and quality of life associated with chronic pain of predominantly neuropathic origin in the community. Clin J Pain. 2007;23(2):143-149.

38. Molsted S, Tribler J, Snorgaard O. Musculoskeletal pain in patients with type 2 diabetes. Diabetes Res Clin Pract. 2012;96(2):135-140.

39. Gerbershagen HJ, Ozgur E, Straub K, et al. Prevalence, severity, and chronicity of pain and general health-related quality of life in patients with localized prostate cancer. Eur J Pain. 2008;12(3):339-350.

40. Forsythe LP, Alfano CM, George SM, et al. Pain in long-term breast cancer survivors: the role of body mass index, physical activity, and sedentary behavior. Breast Cancer Res Treat. 2013;137(2): 617-630.

41. Kim YS, Do H, Lee JW, et al. Patient reporting pain intensity immediately after surgery can be associated with underlying depression in women with breast cancer. Psychooncology. 2016;25(3):308-315.

42. Borge CR, Wahl AK, Moum T. Association of breathlessness with multiple symptoms in chronic obstructive pulmonary disease. $J A d v$ Nurs. 2010;66(12):2688-2700.

43. Chen YW, Camp PG, Coxson HO, et al. Comorbidities that cause pain and the contributors to pain in individuals with chronic obstructive pulmonary disease. Arch Phys Med Rehabil. 2017;98(8):1535-1543.

44. Liao ZT, Pan YF, Huang JL, et al. An epidemiological survey of low back pain and axial spondyloarthritis in a Chinese Han population. Scand J Rheumatol. 2009;38(6):455-459.
Journal of Pain Research

\section{Publish your work in this journal}

The Journal of Pain Research is an international, peer reviewed, open access, online journal that welcomes laboratory and clinical findings in the fields of pain research and the prevention and management of pain. Original research, reviews, symposium reports, hypothesis formation and commentaries are all considered for publication.

\section{Dovepress}

The manuscript management system is completely online and includes a very quick and fair peer-review system, which is all easy to use. Visit http://www.dovepress.com/testimonials.php to read real quotes from published authors. 